\title{
Impacts of Abusing Drugs on Our Society
}

Asif Bilal ${ }^{1 *}$, Muhammad Imran Anjum ${ }^{1}$, Nimra Naveed ${ }^{2}$, Muhammad Saif-ur-Rehman ${ }^{3}$, Umer Ali ${ }^{1}$, Anisa Iftikhar ${ }^{1}$

${ }^{1}$ Department of Zoology, University of Lahore, Sargodha Campus, Sargodha, Pakistan

${ }^{2}$ Department of Zoology, Wildlife and Fisheries, University of Agriculture, Faisalabad, Pakistan

${ }^{3}$ Department of Cardiology, Shaikh Zayed Teaching Hospital, Lahore, Pakistan

Correspondence to: Asif Bilal, Department of Zoology, University of Lahore, Sargodha Campus, Sargodha, Pakistan. Received date: June 24, 2021; Accepted date: July 1, 2021; Published date: July 8, 2021

Citation: Bilal A, Anjum MI, Naveed N, et al. (2021) Impacts of Abusing Drugs on Our Society. J Med Res Surg 2(3): pp. 1-3. doi: 10.52916/jmrs214049

Copyright: (C2021 Bilal A, et al. This is an open-access article distributed under the terms of the Creative Commons Attribution License, which permits unrestricted use, distribution and reproduction in any medium, provided the original author and source are credited.

\section{ABSTRACT}

Alcohol, heroin, inhalants and similar are considered as drug of abuse in our society. These can ruin the lives of everyone. Infact these are slow poisons. Mostly teen agers are big victims of these drugs. They may be more likely to engage in harmful behavior. Alcohol, cigarettes, and crack cocaine are the most often consumed drugs by young people. Our objectives are to identify the effects of abusing drugs in our society and play a role to stop it. The study was done in the Faisalabad division by the interviews of people who were drug addicts through the questionnaire. This survey research was completed in March 2020 to June 2020. We interviewed about 450 drug addicts and we have found about six abusing drugs among those. The drugs were alcohol, heroin, marijuana, allergic injection, inhalant and opium and the percentage of addicts were $24,30,15,14,10$ and 07 respectively. We also found $9 \%$ females and $91 \%$ males were involve and $25 \%$ were teen ager, $60 \%$ were between 20 to 40 years and $15 \%$ were above 40 years. It is concluded that authorities should play their role to stop this sin and it should be established a number of centers for treatment of the drug addicts.

\section{Keywords:}

Drugs, Alcohol, Heroin, Addict, Inhalant, Marijuana, Opium

\section{Introduction}

Alcohol marketing has long been suspected of encouraging underage drinking by researchers and policymakers. Despite the fact that alcohol marketing and advertising are allegedly intended solely at adults. Young people's brains continue to develop and grow before they're in their mid-twenties [1]. This is particularly true of the prefrontal cortex, which is responsible for decision-making. Taking drugs when people are young can cause problems with the brain's development. It may also have an impact on their decision-making. They may be more likely to engage in harmful behavior, such as unsafe sex or irresponsible driving. The earlier young individuals begin taking drugs, the more likely they are to continue using them and develop an addiction later in life [2]. Using drugs when people are young can lead to future health concerns like heart disease, high blood pressure, and sleep disturbances. Alcohol, cigarettes, and crack cocaine are the most often consumed drugs by young people [3]. Vamping tobacco and marijuana has become more popular among young people in recent years. We still don't know a lot about the consequences of vamping. Some people have become very ill or even died as a result of vamping. As a result, young people should refrain from puffing. There are following symptoms of drug [4].

Having a lot of different friends, spending a lot of time alone and losing interest in activities you used to enjoy, not caring for themselves, such as not showering, changing clothes, or cleaning their teeth $[5,6]$. They are frequently exhausted and depressed and eating more or less frequently than usual, being feisty, speaking quickly, or expressing things that don't make sense, having a sour mood, changing from a terrible to a pleasant mood in a matter of seconds, not showing up for critical meetings, having difficulties at school, such as missing classes or receiving poor marks, they have issues with their personal or family relationships, theft and cheating, memory lapses, lack of attention, coordination issues, slurred speech, and so on [7].

\section{Objectives}

The aim and objectives of our study is to identify the effects of abusing drugs in our society and play a role to stop it.

\section{Methodology}

The study was done in the following districts (Faisalabad, Shorkot, Chiniot, Jhang, Jaranwala and Gojra) by the interviews of people who were drug addicts through the questionnaire. Addict prisons were not investigated This survey research was conducted between March 2020 and June 2020. The study areas were selected random. People of rural and urban areas whose are addict of these drugs, are interviewed and they are asked these questions like which type of medicine/drug do they use, Do they use any abusing medicines/drugs, How is their academic performance before and after use of medicines/ drugs, do they ever feel guilty about your medicines/drugs use, Have they been able to stop using medicine/drugs when you want, Have medicines/drugs created problems between you and your friend/family, have they ever felt trouble at work due to use of drugs, have they been arrested because of medicines/ drugs, do they want to stop this addiction, do they have any medical problem due to this habit, do they have any treatment to get rid of using medicines/drugs, what do you want to say about medicines/drugs addiction and much more questions like these (Table 1).

\section{Results}

The data was collected following cities of division Faisalabad 
Table 1: Questionnaire.

\begin{tabular}{|l|l|}
\hline Questions which are asked & Top answers \\
\hline Which type of medicine/drug do you use? & Alcohol, heroin, inhalant, marijuana, opium \\
\hline Do you use any abusing medicines/drugs? & Yes \\
\hline How is your academic performance before and after use of medicines/drugs? & It effects very badly \\
\hline Do you ever feel guilty about your medicines/drugs use? & Yes \\
\hline Have you been able to stop using medicine/drugs when you want? & Probably not \\
\hline Have you been arrested because of medicines/drugs? & Yes, mostly \\
\hline Have medicines/drugs created problems between you and your friend/family? & Yes of course \\
\hline Have you ever felt trouble at work due to use of medicines/drugs? & Yes \\
\hline Do you want to stop this addiction? & Yes but it's hard to stop \\
\hline Do you have any treatment to get rid of using medicines/drugs? & Yes but it's less effective \\
\hline Do you have any medical problem due to this habit? & Yes, mostly brain issues \\
\hline What do you want to say about medicines/drugs addiction? & It is very bad habit \\
\hline
\end{tabular}

randomly like Faisalabad, Shorkot, Chiniot, Jhang, Jaranwala and Gojra. It was not based on counting of drug addicts, it was only based on impacts of these drugs on their lives and which is the most common and dangerous drug. We interviewed about 450 drug addicts and we have found about six abusing drugs among those. The drugs were alcohol, heroin, marijuana, allergic injection, inhalant and opium and the percentage of addicts were $24,30,15,14,10$ and 7 respectively. Addicts of heroin were comparatively found more than other (Figure 1).

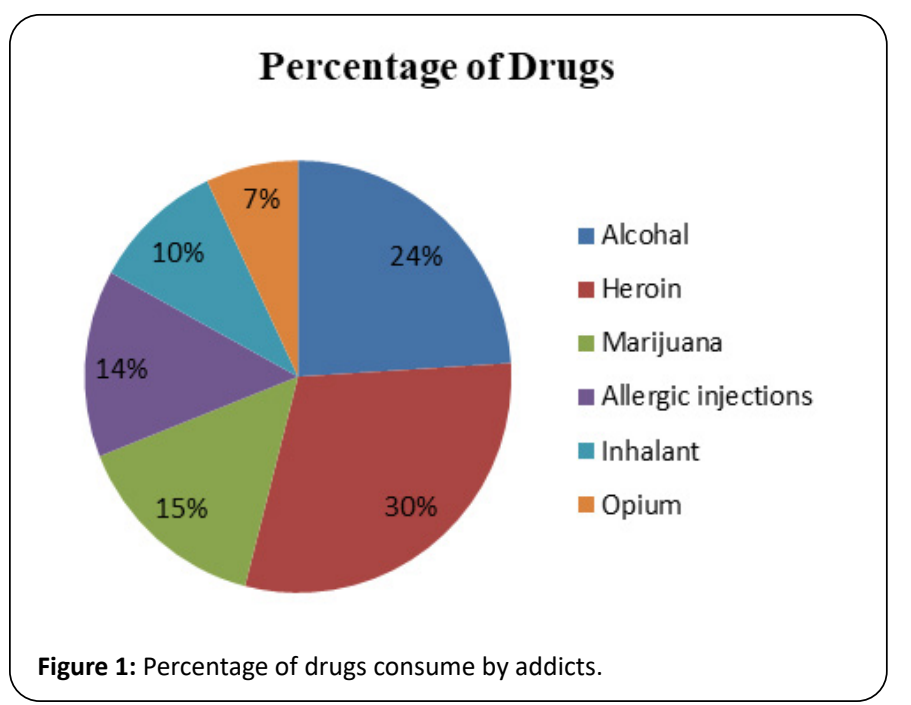

The was an important question about their medical condition during the usage of drugs and many problems were found like weakness, abdominal pain, kidney swelling, loss of self-control, brain issues and even coma or death. Most of the drug addicts were arrested by police. They feel guilty for this bad habit and about $70 \%$ people try to get rid of this but they can't.

A number of educated people were also found in this bad habit we analyzed that the drug impact very badly on their careers. According to their answers we explored that they have following problem like lack of confidence, bad academic performance, face the failure and no brain control.

In our findings, $9 \%$ females and $91 \%$ males were involve. If we say about age factor $25 \%$ were teen ager, $60 \%$ were between 20 to 40 years and $15 \%$ were above 40 years (Figure 2).

\section{Age percentage}

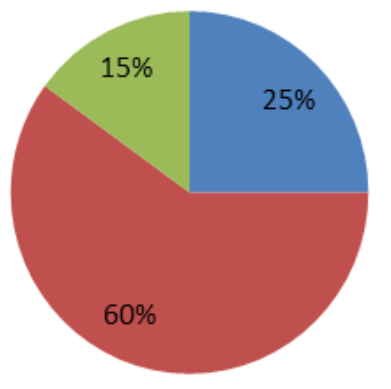

- Teen ager

20-40 years

Above 40 years

Figure 2: Total people involved by age.

Their survival is very difficult, in fact, most of them died at a young age.

\section{Discussion}

Drug usage can have major health repercussions at any age, but teenagers are especially vulnerable [8]. Drug-abusing teenagers are more prone to develop an addiction later in life and suffer from persistent and irreparable brain damage. Other detrimental consequences of juvenile drug addiction include: anxiety, despair, mood swings, suicidal thoughts, and schizophrenia can all be caused or masked by drug usage. In fact, 34.6 percent of youth with serious depression say they use drugs. Unfortunately, substance abuse can exacerbate the severity of these mental issues. Teens who use marijuana on a weekly basis, for example, have a twofold increased risk of despair and anxiety [9]. Adolescents who use drugs are more likely to experience social issues, sadness, suicide thoughts, and violence. Those who abuse drugs are more likely than teens who do not abuse drugs to participate in delinquent behaviors such as fighting and stealing, according to a recent poll by the Substance Abuse and Mental Health Services Administration.

According to studies, the younger a person starts taking drugs, the more likely they are to have a substance abuse issue and relapse later in life. Those who use drugs are five times more likely than teens that do not use drugs to have sex. Teens, 
which use drugs are also more prone to engage in unprotected sex and engage in sex with strangers. STDs, teen pregnancy, and sexual assault have all increased as a result of this.

Drug usage harms both short- and long-term memory, which can lead to learning and memory issues later in life.

Teens that use needles to take drugs put themselves at danger for blood-borne infections like HIV, AIDS, and Hepatitis B and C. Teen drug misuse can lead to significant mental illnesses or permanent, irreversible brain or nervous system damage. Brain shrinkage, poor learning capacities, amnesia and memory problems, impaired thinking, perception, and intuition, increased or decreased socializing, and changes in sexual desire are all symptoms of drug addiction in teenagers [10].

Drug-abusing teenagers are more likely to be involved in car accidents, which can result in serious injury or death. According to one study, 4 to $14 \%$ of drivers who are injured or killed in car accidents test positive for THC.

\section{Conclusion}

It is concluded that authorities should play their role to stop this sin and it should be established a number of centers for treatment of the drug addicts. Drug misuse is a complicated issue that involves not only the sale and trafficking of illicit substances, but also the disruption of the manufacturing and trafficking chain by arresting individuals who manufacture, import, and sell narcotics. Psychological care for drug users and their families is also necessary, but prevention through public awareness campaigns and health risk information to the general public plays a crucial role. It's also important to be able to respond to the question, "Why do people consume drugs?" Understanding the psychosocial reasons that lead people to use drugs, particularly young people, would help us identify where to intervene in society with targeted information campaigns as well as support services such as therapy.

\section{Conflict or interest:}

The authors declare that they have no conflict or interest.

\section{Funding:}

None.

\section{References}

1. Elmore KC, Scull TM, Kupersmidt JB (2017) Media as a "super peer": How adolescents interpret media messages predicts their perception of alcohol and tobacco use norms. J Youth Adolesc 46: pp. 376-387.

2. Campbell LF, Wilmoth K, Mason M (2015) Association of exposure to neighborhood drug activity, neurobehavioral traits, and marijuana use among at-risk African American females. Addict Beh 50: pp. 45-50.

3. Fazio RH (1995) Attitudes as object-evaluation associations: Determinants, consequences, and correlates of attitude accessibility. In Petty RE, Krosnick JA (Eds.), Ohio State University series on attitudes and persuasion, Attitude strength: Antecedents and consequences: pp. 247-282.

4. Erevik EK, Pallesen S, Andreassen CS et al. (2018) Who is watching user-generated alcohol posts on social media? Addict Behav 78: pp. 131-137.

5. Lynskey MT, Vink MJ, Boomsma DI (2006) Early onset cannabis use and progression to other drug use in a sample of Dutch twins. Behav Genet 36(2): pp. 195-200.

6. Timberlake DS, Haberstick BC, Hopfer CJ, et al. (2007) Progression from marijuana use to daily smoking and nicotine dependence in a national sample of U.S. adolescents. Drug Alc Depend 88: pp. 272-281.

7. Jessor R, Jessor SL, Finney J (1973) A social psychology of marijuana use: longitudinal studies of high school and college youth. J Pers Soc Psychol 26(1): pp. 1-15.

8. Glasman LR, Albarracín D (2006) Forming attitudes that predict future behavior: A meta-analysis of the attitudebehavior relation. Psychol Bull 132: pp. 778-822.

9. Lynskey MT, Health AC, Bucholz KK, et al. (2003) Escalation of drug use in early-onset cannabis users vs. co-twin controls. JAMA 289(4): pp. 427-433.

10. Goldman MS, Del Boca FK, Darkes J (1999) Alcohol expectancy theory: The application of cognitive neuroscience. In: Leonard KE, Blane HT (Eds.), Psychological Theories of Drinking and Alcoholism : pp. 164-202. 